\title{
The genomic evaluation system in the United States: Past, present, future
}

\author{
G. R. Wiggans, ${ }^{1}$ P. M. VanRaden, and T. A. Cooper \\ Animal Improvement Programs Laboratory, Agricultural Research Service, USDA, Beltsville, MD 20705-2350
}

\begin{abstract}
Implementation of genomic evaluation has caused profound changes in dairy cattle breeding. All young bulls bought by major artificial insemination organizations now are selected based on such evaluation. Evaluation reliability can reach approximately $75 \%$ for yield traits, which is adequate for marketing semen of 2 -yr-old bulls. Shortened generation interval from using genomic evaluations is the most important factor in increasing the rate of genetic improvement. Genomic evaluations are based on 42,503 single nucleotide polymorphisms (SNP) genotyped with technology that became available in 2007. The first unofficial USDA genomic evaluations were released in 2008 and became official for Holsteins, Jerseys, and Brown Swiss in 2009. Evaluation accuracy has increased steadily from including additional bulls with genotypes and traditional evaluations (predictor animals). Some of that increase occurs automatically as young genotyped bulls receive a progeny test evaluation at $5 \mathrm{yr}$ of age. Cow contribution to evaluation accuracy is increased by decreasing mean and variance of their evaluations so that they are similar to bull evaluations. Integration of US and Canadian genotype databases was critical to achieving acceptable initial accuracy and continues to benefit both countries. Genotype exchange with other countries added predictor bulls for Brown Swiss. In 2010, a low-density chip with 2,900 SNP and a high-density chip with 777,962 SNP were released. The low-density chip has increased greatly the number of animals genotyped and is expected to replace microsatellites in parentage verification. The high-density chip can increase evaluation accuracy by better tracking of loci responsible for genetic differences. To integrate information from chips of various densities, a method to impute missing genotypes was developed based on splitting each genotype into its maternal and paternal haplotypes and tracing their inheritance through the pedigree. The same method is used to impute genotypes of nongenotyped dams based on genotyped progeny and mates. Reliability of resulting evaluations is discounted to reflect errors inherent
\end{abstract}

Received September 27, 2010.

Accepted March 4, 2011.

${ }^{1}$ Corresponding author: George.Wiggans@ars.usda.gov in the process. Further increases in evaluation accuracy are expected because of added predictor animals and more SNP. The large population of existing genotypes can be used to evaluate new traits; however, phenotypic observations must be obtained for enough animals to allow estimation of SNP effects with sufficient accuracy for application to the general population.

Key words: genomic evaluation, SNP effect, reliability

\section{INTRODUCTION}

Genetic evaluation of dairy cattle has provided the means for steady genetic improvement in production, fitness, and conformation traits. The evaluations have been based on milk recording and breed association programs for type traits. Widespread use of superior bulls through AI has been the primary vehicle for progress. Identification of superior bulls has been expensive and time consuming because of the need to wait for milking daughters and the cost of collecting their data to achieve an evaluation of adequate accuracy. The great promise of DNA analysis has recently become a reality with the advent of low-cost genotyping of large numbers of SNP markers. The history of this development, current application in dairy cattle, and expected future developments are presented.

\section{HISTORY}

For many years and many species, DNA markers have been used for research and as parentage verification. Parentage verification began with analysis of blood groups (Stormont, 1967) and transitioned to microsatellite markers (Dekkers, 2004). Marker-assisted selection, which uses linkage relationships between markers and QTL to provide genomic information for traits of interest (Soller, 1994), has been investigated for use in breeding programs but has had only modest commercial value because of the cost and difficulties associated with marker validation (Misztal, 2006). For livestock, the search for major genes related to quantitative traits has had limited success, because only a small portion of genetic variation can be explained by the collection of markers investigated (Andersson, 2001). For dairy cattle, most traits of economic importance 
are controlled by many genes, each of small effect (Cole et al., 2009; Hayes et al., 2010). Because gene effects are small, a large amount of data is needed to estimate the effects accurately, and dense markers are needed to ensure that the association between marker and QTL persists across families.

The critical change was the development of assays that can be used to genotype large numbers of SNP at low cost. Although SNP are only biallelic (2 states), the large number available allows tracking the inheritance of short chromosomal segments. An international consortium of government, university, and industry cooperators worked with Illumina (San Diego, CA) to develop a set of SNP to be included on a chip (Van Tassell et al., 2008). A commercial set of 54,001 was included in the original release of the BovineSNP50 BeadChip (Illumina, 2010b). Consortium members had access to the new chip in fall 2007, and it became publicly available in late December 2007. In July 2010, Illumina released 2 new genotyping chips: a low-density chip (Bovine3K) with 2,900 SNP (Illumina, 2010c) and a high-density chip (BovineHD) with 777,962 SNP (Illumina, 2010a).

Genotypes from chips processed at the Beltsville Agriculture Research Center (MD), University of Missouri (Columbia), and University of Alberta (Edmonton, $\mathrm{AB}$, Canada) were used in initial research to determine which SNP should be used in genomic evaluation. Some SNP were excluded because of low call rate, poor calling properties, or high correlation with other SNP (Wiggans et al., 2009b). Procedures were developed to check for parent-progeny conflicts and other inconsistencies (Wiggans et al., 2010b). Extensive simulation work by VanRaden (2008), which was based on the research of Meuwissen et al. (2001), enabled development of genomic evaluation methods, which were applied once genotypes became available for US dairy cattle. The phenotypic and genotypic information for a predictor population was used to estimate SNP effects. Predictor animals are genotyped animals with traditional evaluations (i.e., they do not include genomic information). The SNP effects estimated from a predictor population can be used to calculate genomic evaluations for animals without traditional evaluations (VanRaden, 2008; VanRaden et al., 2009). A nonlinear option allows for a heavy-tailed distribution of SNP effects to accommodate any trait on which a single gene has a large effect. The first unofficial USDA evaluations based on SNP genotypes were released in April 2008. Genomic evaluations became official for Holsteins and Jerseys in January 2009 and for Brown Swiss in August 2009.

The money to genotype thousands of animals came from research grants and contributions from AI and breed organizations. In return for their support, the AI organizations received the exclusive right to have males genomically evaluated until May 2013. The commercial laboratories of GeneSeek (Lincoln, NE) and Genetics \& IVF Institute (Fairfax, VA) participated in the initial genotyping and processing of commercial samples. They were joined later by DNA LandMarks (Saint-Jean-surRichelieu, QC, Canada), Genetic Visions (Middleton, WI), and Expression Analysis (Durham, NC).

Many countries have adopted the use of genomic information in their genetic evaluations (Loberg and Dürr, 2009). Canada collaborated with the United States in developing genomic evaluations based on BovineSNP50 genotypes (Wiggans et al., 2009a) and released official genomic evaluations in 2009 (Van Doormaal et al., 2009). France first used microsatellite markers in a marker-assisted selection program in 2001 and then began using a relatively small number of SNP for unofficial evaluations in 2008 (Ducrocq et al., 2009). The Netherlands uses SNP from a customized Illumina chip (de Roos et al., 2009) as well as the BovineSNP50 BeadChip (Interbull, 2010). New Zealand was an early adopter of the BovineSNP50 chip for its evaluation system and has encouraged widespread use of young genomically evaluated bulls (LIC, 2008); Australia plans to release official genomic evaluations in 2011 (Nieuwhof et al., 2010). Germany has implemented a genomic evaluation system (Reinhardt et al., 2009), and Italy and Switzerland expect to provide genomic evaluations in 2011 (Loberg and Dürr, 2009).

A cooperative endeavor called EuroGenomics was established in 2009 by 5 European breeder-owned companies that represent Belgium, Denmark, Finland, France, Germany, the Netherlands, and Sweden (David et al., 2010). The goal was to share genotypes for predictor bulls, thus improving evaluation accuracy in each participating country. As part of the cooperative effort, a system was developed to allow data exchange between the BovineSNP50 BeadChip and the customized Netherlands chip (Druet et al., 2010). Predictor population numbers reported by countries that participated in the Interbull validation test for genomic evaluations of protein yield (Interbull, 2010) in August 2010 are shown in Table 1. In December 2010, EuroGenomics (2010) extended its collaborative effort and now has a predictor population of 18,300 bulls.

\section{EVALUATION PROCESS}

\section{Nomination}

Since 2007, genotypes that were usable for genetic evaluations have been received by USDA for $>70,000$ animals as of December 2010 (Table 2). The availability of the Bovine3K chip has greatly increased the number 
Table 1. Numbers of animals with genotypes and traditional evaluations that were used to estimate effects of SNP (predictor populations) in August 2010 for Interbull validation of genomic evaluations for protein yield ${ }^{1}$ by country, breed, and animal sex

\begin{tabular}{|c|c|c|c|c|c|c|}
\hline \multirow[b]{2}{*}{ Country } & \multicolumn{2}{|c|}{ Holstein } & \multicolumn{2}{|c|}{ Jersey } & \multicolumn{2}{|c|}{ Brown Swiss } \\
\hline & Bulls & Cows & Bulls & Cows & Bulls & Cows \\
\hline Canada $^{2}$ & NA & - & - & - & - & - \\
\hline Denmark, Finland, and Sweden ${ }^{3}$ & 10,217 & - & - & - & - & - \\
\hline France $^{4}$ & NA & - & - & - & - & - \\
\hline Germany, Austria, and Luxembourg ${ }^{5}$ & 17,477 & - & - & - & - & - \\
\hline the Netherlands ${ }^{6}$ & 16,173 & - & - & - & - & - \\
\hline United States $^{9}$ & 9,958 & 8,122 & 2,088 & 740 & 1,215 & 116 \\
\hline
\end{tabular}

${ }^{1}$ Interbull (2010).

${ }^{2}$ Predictor population for Holsteins as of July 2010 was based on bulls, but number of bulls was not available (NA); predictor population of bulls as of December 2010 was 10,667 for Holsteins, 2, 049 for Jerseys, and 1,527 for Brown Swiss (G. Kistemaker, Canadian Dairy Network, Guelph, ON, Canada, personal communication).

${ }^{3}$ Predictor population as of July 2010 that included animals from Austria, Denmark, Finland, France, Germany, Luxembourg, the Netherlands, and Sweden.

${ }^{4}$ Predictor population for Holsteins as of February 2010 was based on bulls; France also had Montbéliard and Normande predictor populations. ${ }^{5}$ Predictor population as of July 2010 that included animals from Austria, Denmark, Finland, France, Germany, Luxembourg, the Netherlands, and Sweden.

${ }^{6}$ Predictor population as of July 2010 that included animals from Austria, Denmark, Finland, France, Germany, Luxembourg, the Netherlands, Sweden, and the United States.

${ }^{7}$ Predictor populations as of May 2010; New Zealand also had a Holstein-Jersey crossbred predictor population.

${ }^{8}$ Predictor population as of May 2010 (A. Żarnecki, National Research Institute of Animal Production, Balice k. Krakowa, Poland, personal communication).

${ }^{9}$ Predictor populations as of June 2010 that included Holsteins from Canada, the United States, and 16 other countries; Jerseys from Australia, Canada, Denmark, New Zealand, and the United States, and Brown Swiss from Switzerland, the United States, and 6 other countries.

of animals genotyped, and its SNP are expected to replace microsatellites for parentage verification. From September through December 2010, almost 12,000 Bovine3K chip genotypes (8,947 Holstein and 3,033 Jersey) were received (not shown); $92 \%$ of those genotypes were for females. The 8 AI and 4 breed organizations that arrange for genotyping are designated as requesters. They arrange for a DNA sample to be collected and attached to a bar-coded mailer. That mailer is usually sent to the requester but may be sent directly to the genotyping laboratory. The bar code facilitates sample processing at the laboratory. The requester is expected to nominate each animal by making an entry in a database maintained by USDA's Animal Improvement Programs Laboratory (AIPL) before the sample reaches the genotyping laboratory. The nomination is either through a web interface or pedigree records containing the bar code (also known as sample identification). The breed associations use the pedigree record option for almost all of their nominations, as do several of the larger AI organizations. All requesters use the nomination query for nomination confirmation and update and for problem resolution. The nomination process ensures that the pedigree for the animal is in the AIPL database before the genotype arrives at AIPL and simplifies matching the identification associated with the genotype with the animal's information in the AIPL database.

\section{Genotyping}

At the genotyping laboratories, DNA is extracted from the sample. In 2010, DNA sources included hair $(82 \%)$, nasal swab $(12 \%)$, blood $(5 \%)$, semen $(<1 \%)$, and ear punches $(<1 \%)$. The process of DNA amplification and fragmentation, hybridization to the chip, labeling, and genotype detection takes $3 \mathrm{~d}$. Data generated from the laser reader then are clustered to determine SNP genotypes (Illumina, 2010b). Those genotypes and corresponding identification information are transferred to AIPL.

\section{Genotype Storage and Validation}

The AIPL database can store multiple genotypes for an animal and relies on chip identification and sample location on the chip to identify a sample uniquely. Multiple samples arise from collection and labeling errors as well as upgrading from lower to higher density. As samples are loaded, they are checked on an animal basis for call rate and parent-progeny conflicts. In addition to conflicts with reported parents, a conflict also is designated if comparison with all other genotypes indicates that an animal has a parent-progeny relationship that is not found in the pedigree (usually the genomically correct parent). A report of SNP with a call rate of $<90 \%$, a departure from Hardy-Weinberg equilibrium 
Table 2. Numbers of genotyped animals by breed and evaluation date

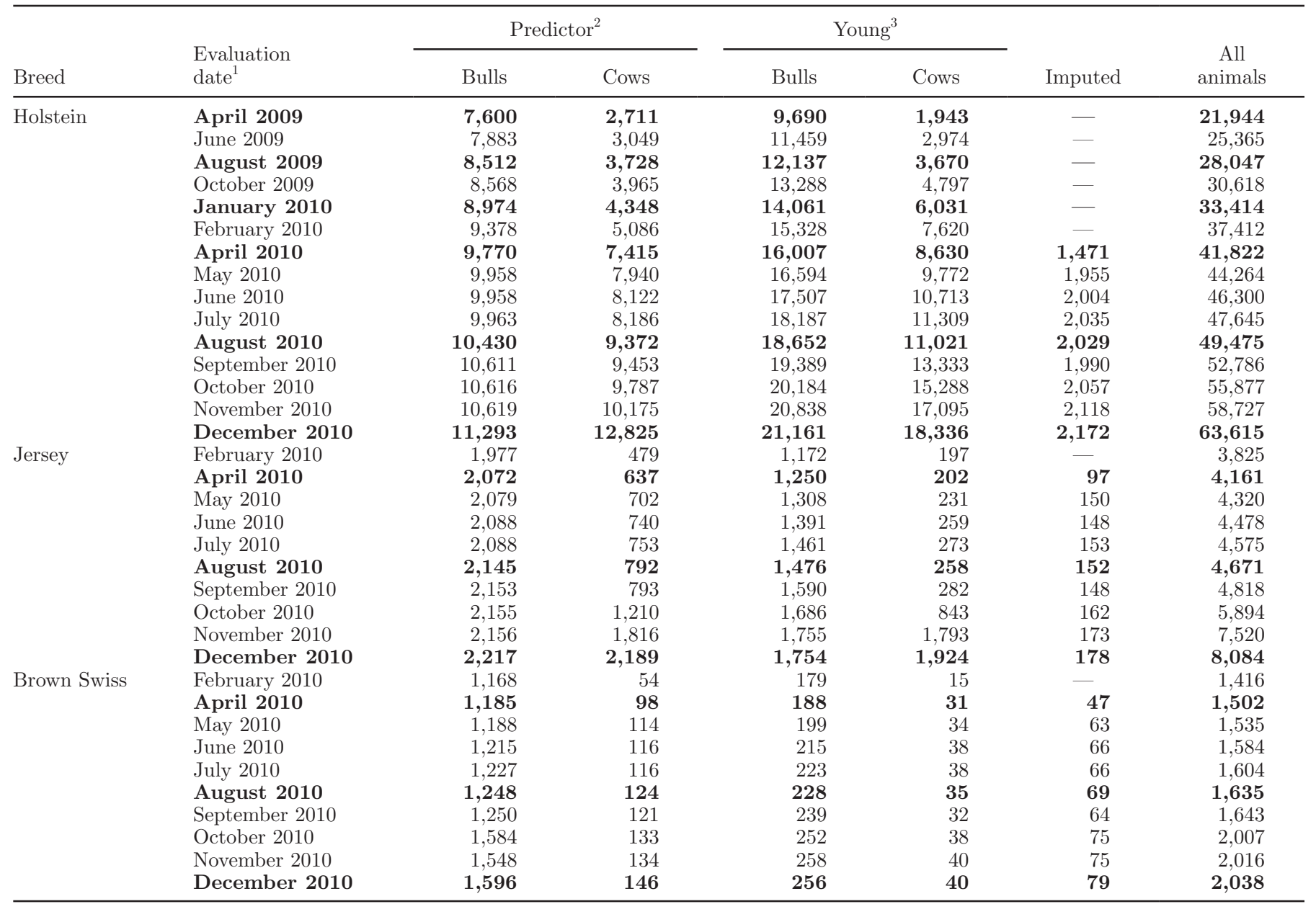

${ }^{1}$ Evaluation dates in boldface are official USDA-DHIA evaluation releases that update traditional evaluations.

${ }^{2}$ Animals with traditional evaluations (no genomic information included).

${ }^{3}$ Animals without traditional evaluations.

(difference between number of expected and actual heterozygous SNP), or parent-progeny conflicts of $>2 \%$ is returned to the submitting laboratory. Those checks serve as a measure of the quality of the genotype calls. For BovineSNP50 genotypes, usually $<10$ SNP were outside those limits for any submission. Based on initial submission results, laboratories often were successful in reclustering problematic SNP to decrease the number of SNP conflicts in those categories. For Bovine3K genotypes, considerable effort was required to determine which SNP were reliable and to adjust procedures to achieve results similar to those for BovineSNP50 genotypes.

The database allows for storage of genotypes from chips with differing numbers of SNP. Currently, the Bovine3K, BovineSNP50, and BovineHD chips are supported. Comparisons of SNP genotypes from different chips are supported but limited to SNP in common.
Many conflicts can be resolved. For most cases of sire conflict, an alternative sire is suggested. Identical genotypes often are the result of embryo splits or identical twins. Because bulls have only one X chromosome, their genotypes for X-specific SNP appear to be homozygous, and that characteristic is used in sex validation. Some cows inherit both of their $\mathrm{X}$ chromosomes from the same male ancestor and, therefore, appear to be males. If a common male ancestor can be found, genotypes for such cows are accepted. The Bovine3K chip includes Y-specific SNP, which are used in sex validation. Usability of genotypes is evaluated whenever pedigree of a genotyped animal changes.

\section{Genotype Preparation}

The SNP genotypes for each animal (42,503 SNP for BovineSNP50 genotypes, 38,201 SNP for BovineHD 
genotypes, and 2,614 SNP for Bovine3K genotypes) are extracted from the database. Because the number of animals with high-density genotypes is too few for routine evaluation, only the 38,201 SNP that match the BovineSNP50 chip currently are extracted. During extraction, multiple genotype calls for an individual animal are merged, with preference given to the genotype with the highest call rate. Identical twins and animals from split embryos have their genotypes harmonized. For dams without genotypes, genotypes are imputed (constructed from relatives) if the number of genotyped progeny and mates is sufficient to reach a call rate of $90 \%$ on an allele basis. Since April 2010, dams with imputed genotypes have been included in genomic evaluations. Imputation also is used to add genotypes for SNP that are on the BovineSNP50 but not the Bovine3K chip. Imputation involves splitting the genotype into paternally and maternally contributed chromosomes (haplotypes). Haplotype inheritance is traced and used to fill in missing genotypes. When pedigree sources are not available, the most common, consistent haplotype in the population is selected. Table 2 shows the number of usable genotypes by breed for most of the genomic evaluations released since April 2009.

\section{Estimation of SNP Effects}

The effects of SNP on traditional evaluations are estimated for $>30$ traits. The traditional evaluations are deregressed so that shrinkage based on amount of information, which is inherent to estimation of random effects, is undone to make the data more like individual records. Cow and bull evaluations must be comparable, because both are used to estimate SNP effects. Therefore, traditional evaluations of Holstein and Jersey cows for milk, fat, and protein yields and component percentages are adjusted to remove overestimation usually associated with cow evaluations for yield traits (Wiggans et al., 2010a). That adjustment makes the mean and variance of the deregressed value for a cow similar to that for a bull with similar accuracy. To do that, the contribution of parent average is removed from the traditional evaluation and then the remainder is deregressed, is multiplied by a number less than 1 to decrease the variance, and has a constant subtracted to decrease the mean.

Deregressed traditional evaluations are regressed on each of the 42,503 SNP genotypes (VanRaden, 2008), where the genotypes are expressed as the quantity of one of the alleles $(0,1$, or 2$)$. Because the effects are considered to be random, a system with more effects than observations is solvable. The solution is the effect on each trait from replacing 1 allele in the SNP genotype with the other allele. In addition to SNP effects, a polygenic effect is estimated to capture genetic variation not accounted for by SNP.

Most SNP have small effects, which are distributed evenly across all chromosomes. For both Holsteins and Jerseys, the largest effects for milk and fat were found on chromosome 14 and were associated with the diacylglycerol O-acyltransferase 1 (DGAT1) gene (Grisart et al., 2004). An increased effect for protein yield was also found on chromosome 14 for Jerseys. Methods for the visualization of SNP effects were described by Cole and VanRaden (2010), and plots of the absolute values of effects for all 42,503 SNP on 31 traits of economic importance are available at the AIPL website (http:// aipl.arsusda.gov/Report_Data/Marker_Effects/marker_effects.cfm).

\section{Calculation of Genomic Evaluation}

An animal's genomic evaluation includes a genomic prediction (estimates of SNP and polygenic effects) and information from traditional evaluations that is not already included in the genomic information. A traditional evaluation is calculated for just the subset of animals with genotypes to allow determination of the traditional information that was accounted for by genomics. A selection index is used to combine the genomic prediction, traditional evaluation, and subset evaluation (VanRaden et al., 2009).

\section{Measure of Accuracy}

Reliability measures how much information contributes to the evaluation. For genomic evaluations, reliability combines daughter equivalents from genomics, parent average, and information from the traditional evaluation not accounted for through genomics. The genomic contribution is approximated by a function of the weighted sum of the genomic relationships of the animal with the predictor population. The weight is the reliability with the component for parent average removed. The genomic relationship with predictor animals and their evaluation reliability are the primary determinants of accuracy for genomic evaluations. Thus, the genomic contribution is lower for less related animals, such as those with foreign ancestors or subpopulations that contributed little to the current population (Wiggans and VanRaden, 2010).

The increase in evaluation reliability from including genomic information can be demonstrated by comparing August 2006 traditional parent averages for young bulls without daughter information, their August 2006 genomic evaluations that include SNP and polygenic 
effects estimated from the August 2006 predictor population in addition to their traditional parent average, and their June 2010 daughter deviations deregressed from their traditional evaluations (Table 3). Mean reliability for August 2006 genomic evaluations of young bulls across all yield, health, and fertility (where applicable) traits (not shown) was $57 \%$ for Holsteins, $55 \%$ for Jerseys, and $52 \%$ for Brown Swiss. Gains in reliability above parent average (Table 3) ranged from 2.7 to 47.6 percentage units for Holsteins, 9.6 to 29.2 percentage units for Jerseys, and 3.0 to 25.8 percentage units for Brown Swiss. Reliability gains were lowest for stillbirth, which had the smallest predictor population because cow evaluations were not included and because fewer bulls had evaluations as data collection had begun more recently than for other traits. Coefficients of determination $\left(\mathrm{R}^{2}\right)$ also are provided in Table 3 as a measure of the relationship between 2006 evaluations (either parent average or genomic evaluation) and 2010 daughter deviations (deregressed values). The $\mathrm{R}^{2}$ ranged from 3.1 to 36.7 for parent average and from 9.6 to 62.1 for genomic evaluation. Reliabilities for both parent average and genomic evaluation are higher than their respective $\mathrm{R}^{2}$, because reliability adjusts for error variance (differing amounts of information) and because selection had occurred in the genotyped population. Coefficients for regression of June 2010 daughter deviation on August 2006 genomic evaluations (Table 3 ) ranged from 0.87 to 1.08 for Holsteins, 0.88 to 1.30 for Jerseys, and 0.84 to 1.09 for Brown Swiss; a coefficient close to 1 indicates that a 1-unit difference in the genomic evaluation results in a 1-unit change in the trait. For bias in genomic evaluation (Table 3), a negative value indicates that the initial August 2006 genomic evaluation was higher than the June 2010 deregressed value.

Changes in methodology for genomic evaluation also affect the measure of evaluation accuracy. Implementation of the adjustment for cow evaluations in April 2010 increased the gain in reliability from genomics by about 3 percentage units for Holstein and Jersey yield traits (Wiggans et al., 2010a). The accuracy loss from imputation required to include Bovine3K genotypes required a reliability adjustment. Reliabilities are converted to daughter equivalents and discounted by the lower call rate and loss in accuracy. The adjusted daughter equivalents then are converted back to reliabilities. Predictive ability of genetic merit with a low-density chip with 3,000 equally spaced SNP was reported to be 84 to $89 \%$ of that with the BovineSNP50 chip for Holsteins (Vazquez et al., 2010) and around 95\% for Jerseys (Weigel et al., 2010). In December 2010, reliabilities for official PTA for milk yield, which included all sources of information, ranged from 74 to $81 \%$ for 93\% of young Holstein bulls (Figure 1).

\section{Distribution}

Genomic evaluations are calculated monthly. At each triannual release of official USDA-DHIA evaluations, all genomic evaluations are released. Between those releases, genomic evaluations are released only for new animals or young bulls that are not being marketed so that evaluations of marketed bulls do not fluctuate between official evaluations. Evaluations of bulls that are less than 2 yr old and not enrolled in the cross-reference program of the National Association of Animal Breeders are distributed only to the owners and requesting AI organizations.

\section{FUTURE}

Genomic evaluations are expected to continue to increase in accuracy. The largest contributor to that increased accuracy will be additional predictor animals. Table 2 shows the natural increase in the US predictor population at each official evaluation from bulls with a first progeny-test result at approximately $5 \mathrm{yr}$ of age. The US predictor population also increases the month following evaluation release when newly evaluated foreign bulls can contribute. In addition, the Cooperative Dairy DNA Repository (Ashwell and Van Tassell, 1999) has semen straws for $>10,000$ bulls with traditional evaluations but that have not been genotyped yet. A way may be found to pay for genotyping some of those bulls. Work also continues on how to make information from cows more useful. New Zealand has genotyped all of their bulls and are considering cows as a way to add to their predictor population (Spelman et al., 2010).

In July 2010, Illumina (2010a) released a highdensity chip with 777,962 SNP, and Affymetrix (2011; Santa Clara, CA) released a high-density chip with 648,855 SNP in January 2011. Although such chips can provide genotypes that increase accuracy of genomic evaluations by better tracking of the loci responsible for genetic differences, the accuracy gains are not expected to be large (VanRaden and Tooker, 2010). As with lowdensity SNP, high-density SNP would be imputed from current genotypes. The first step is to collect enough high-density genotypes so that most haplotypes are represented. Several thousand genotyped animals may be required. The ultimate density is full sequencing, and its cost has been decreasing. With full sequencing for a substantial number of animals, SNP that are the causative mutation or are closely linked to it may be identified (Meuwissen, 2010). Identification of those SNP may enable an increase in evaluation accuracy and a decreased number of SNP needed for evaluation. The higher density genotypes may also support genomic evaluations of crossbred cattle, because the SNP may 
Table 3. Observed reliabilities (REL) in August 2006 for traditional parent averages and genomic evaluations ${ }^{1}$ of young bulls without daughter information, coefficients of determination $\left(\mathrm{R}^{2} \times 100\right)$ between August 2006 evaluations and June 2010 daughter deviations deregressed from traditional evaluations, coefficients (b) for regression of June 2010 daughter deviations on August 2006 genomic evaluations, and bias in genomic evaluation by trait and breed

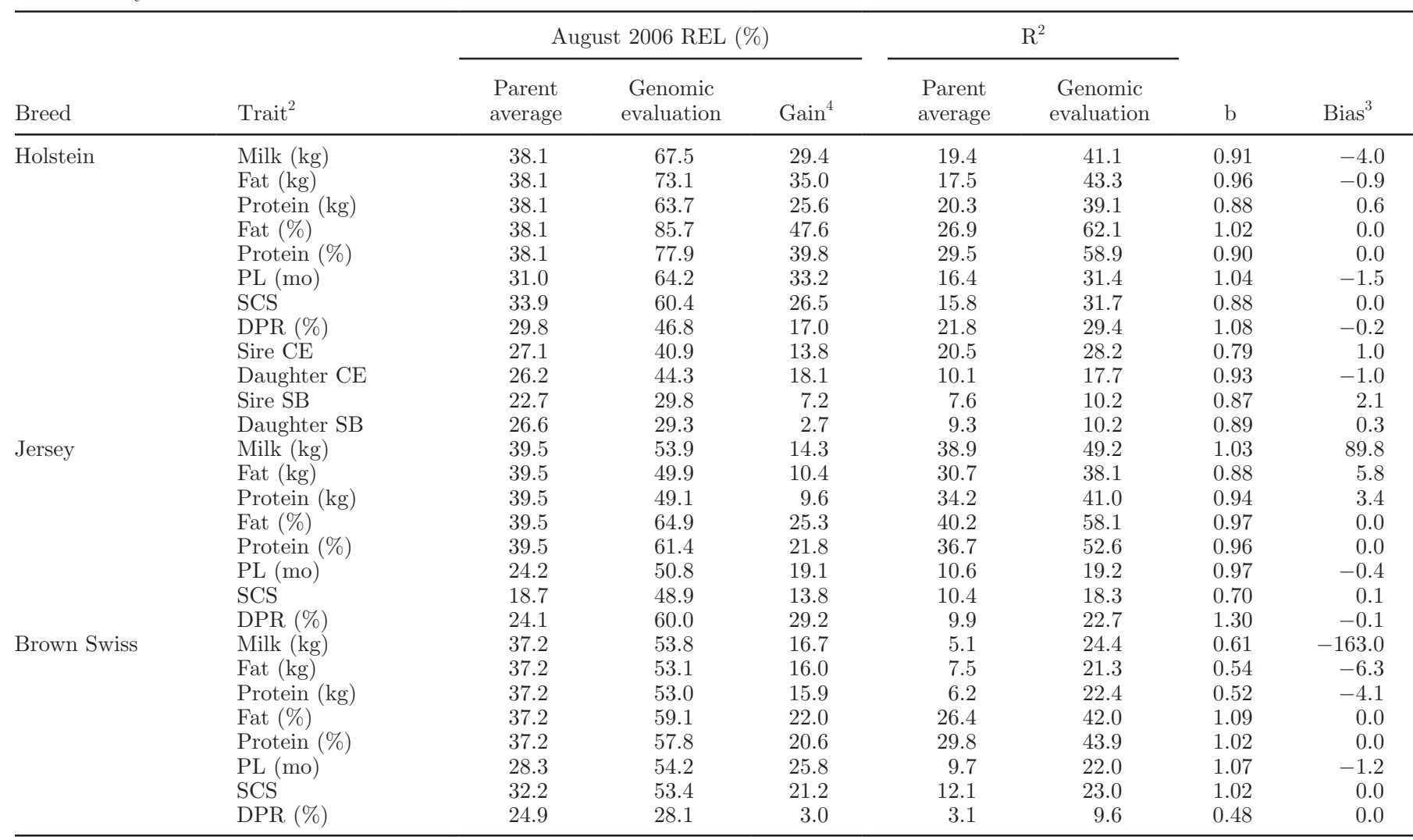

${ }^{1}$ Includes SNP and polygenic effects estimated from the August 2006 predictor population (genotyped animals with traditional evaluations) and August 2006 traditional parent averages.

${ }^{2} \mathrm{PL}=$ productive life, $\mathrm{DPR}=$ daughter pregnancy rate, $\mathrm{CE}=$ calving ease, and $\mathrm{SB}=$ stillbirth.

${ }^{3}$ June 2010 daughter deviation - August 2006 genomic evaluation.

${ }^{4}$ Genomic REL - parent average REL.

be close enough to the QTL that the phase of the association persists across breeds. However, even with accurate tracking of QTL alleles, their effects may differ between breeds.

A method to calculate traditional and genomic evaluations in a single step is being developed (Aguilar et al., 2010). Holstein Association USA plans to adopt that system for conformation evaluations in 2011. A singlestep evaluation system that includes both phenotypic records and genomic information could account for the selection bias that will affect traditional evaluation systems when the only new bulls to receive traditional evaluations are those that have been genomically selected.

\section{Increased Accuracy Through Collaboration}

Collaboration is the least expensive way to increase the predictor population and, thus, increase accuracy.
Collaboration between the United States and Canada was quite successful in initially increasing the size of the predictor population and continues to add to it. Research collaboration has helped to improve evaluation methodology, and coordination across countries has aided with producer acceptance by minimizing differences and explaining existing differences. Genotypes from the United States were traded with Switzerland, Germany, and Austria to increase the number of predictor bulls for Brown Swiss.

As experience with genomics accumulates, the benefit of a larger predictor population becomes apparent. Therefore, groups with small populations look to join larger groups to have evaluations with competitive accuracy, and larger groups see an opportunity to increase accuracy of selection decisions further. EuroGenomics is a collaboration among several European countries, which have a combined predictor population greater than for Canada and the United States. That collabora- 


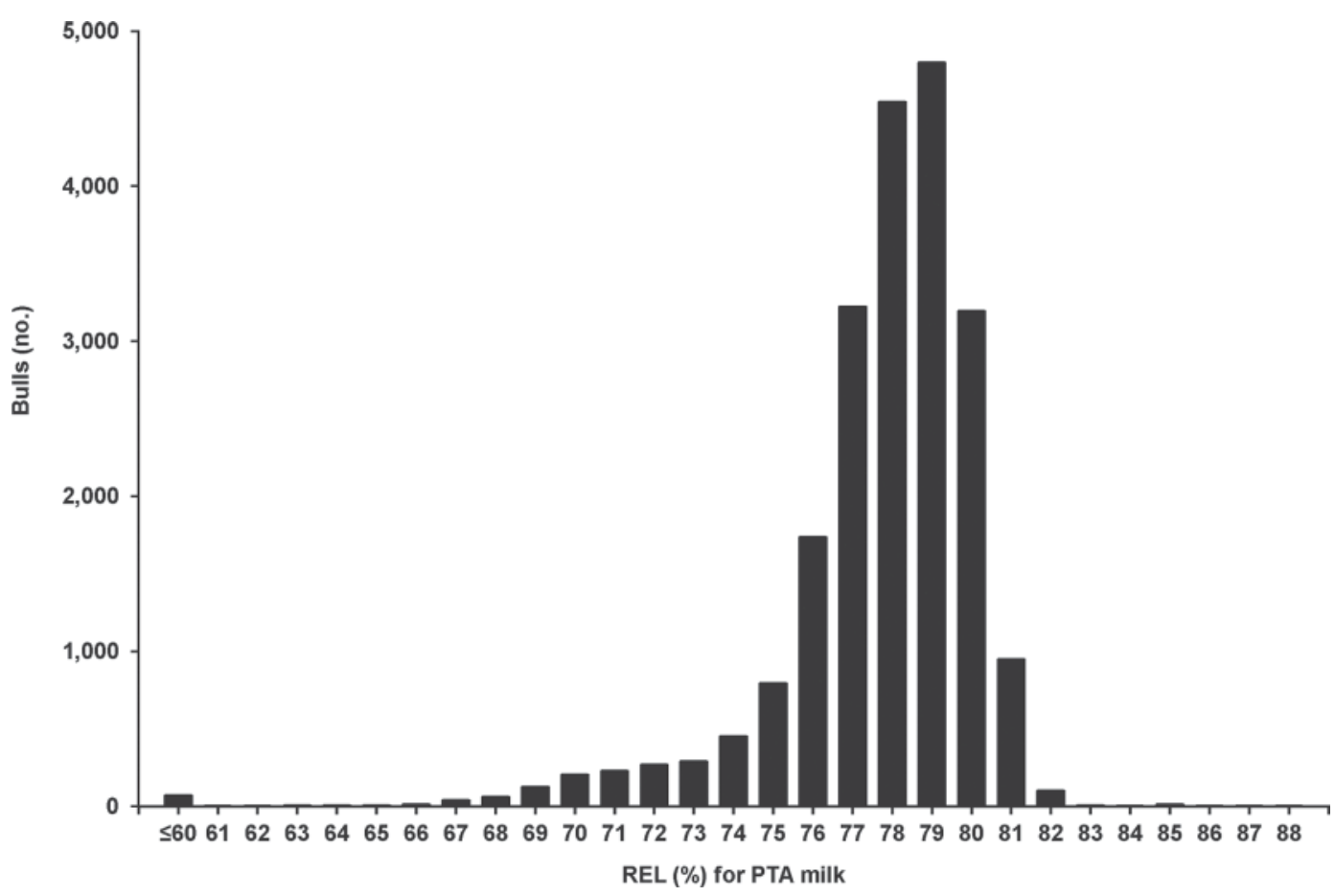

Figure 1. Reliabilities (REL) for PTA for milk yield for young Holstein bulls.

tion has increased interest in North America to increase the predictor population, and discussions are underway for various levels of US collaboration with other countries. The most useful collaborations will be with countries that have used similar sires in recent years, because that would result in the highest relationship of animals with the predictor population. The genetic correlation between countries also is an indicator of the amount of information that a genetic evaluation for an additional predictor animal can provide.

\section{New Traits}

A genotype can be used to evaluate all traits, which suggests that new traits can be easily added to selection objectives. However, genomic evaluations require accurate estimates of SNP effects, which in turn, need accurate traditional evaluations. As milk production becomes increasingly specialized, selection objectives will need to account for more of the traits that affect profitability. Once sufficient data have been accumulated to evaluate a trait genomically, selection can be made at birth (or before) so that the benefit of shortened generation interval and resulting increase in rate of genetic gain can be realized. However, measurement of all traits must be continued to ensure that the SNP effect estimates are appropriate for the current population.

\section{New Applications}

With the increase in availability of genomic evaluations because of the low cost of low-density genotyping, their use is expected to extend beyond the current focus on bull selection by AI organizations, semen marketing for high-ranking bulls without milking daughters, and selection of bull dams. Even at a low price, however, genotyping must have economic value. Only if better decisions can be made will a genomic evaluation be worth the cost. Some possible uses include information for determining which cows to keep in the herd, which to breed to beef bulls, which to breed with sexed semen, and which to flush for embryo transfer as well as marketing information. In addition, inbreeding can be controlled better if more accurate parentage information is available or if female genotypes can be compared with those of potential service sires.

\section{CONCLUSIONS}

Genomic evaluations have revolutionized dairy cattle breeding by greatly increasing the accuracy of estimates of genetic merit for young animals and could double the rate of genetic progress. Those evaluations are based on genotypes that are extensively checked for quality, and conflicts are resolved. They are becoming more accurate as animals are added to the predictor popula- 
tion. All young bulls purchased by major AI organizations now are selected based on genomic evaluations. The development, implementation, and acceptance of genomic evaluations have allowed extensive marketing of 2-yr-old bulls.

\section{ACKNOWLEDGMENTS}

The AIPL staff is thanked for calculating USDADHIA genetic evaluations and conducting the research needed to support them. Suggestions for manuscript improvement by S.M. Hubbard (AIPL, Beltsville, MD) and 2 anonymous reviewers are appreciated.

\section{REFERENCES}

Affymetrix. 2011. Axiom Genome-Wide BOS 1 Array Plate. Accessed January 26, 2011. http://media.affymetrix.com/support/technical/datasheets/axiom_gw_bos1_arrayplate_datasheet.pdf.

Aguilar, I., I. Misztal, D. L. Johnson, A. Legarra, S. Tsuruta, and T. J. Lawlor. 2010. Hot topic: A unified approach to utilize phenotypic, full pedigree, and genomic information for genetic evaluation of Holstein final score. J. Dairy Sci. 93:743-752.

Andersson, L. 2001. Genetic dissection of phenotypic diversity in farm animals. Nat. Rev. Genet. 2:130-138.

Ashwell, M. S., and C. P. Van Tassell. 1999. The Cooperative Dairy DNA Repository - A new resource for quantitative trait loci detection and verification. J. Dairy Sci. 82(Suppl. 1):54 (Abstr.)

Cole, J. B., and P. M. VanRaden. 2010. Visualization of results from genomic evaluations. J. Dairy Sci. 93:2727-2740.

Cole, J. B., P. M. VanRaden, J. R. O'Connell, C. P. Van Tassell, T. S. Sonstegard, R. D. Schnabel, J. F. Taylor, and G. R. Wiggans. 2009. Distribution and location of genetic effects for dairy traits. J. Dairy Sci. 92:2931-2946.

David, X., A. de Vries, E. Feddersen, and S. Borchersen. 2010. International genomic cooperation: EuroGenomics significantly improves reliability of genomic evaluations. Interbull Bull. 41:2 pages. Accessed December 21, 2010. http://www.interbull.org/images/stories/David.pdf.

de Roos, A. P. W., C. Schrooten, E. Mullaart, S. van der Beek, G. de Jong, and W. Voskamp. 2009. Genomic selection at CRV. Interbull Bull. 39:47-50.

Dekkers, J. C. M. 2004. Commercial application of marker- and geneassisted selection in livestock: Strategies and lessons. J. Anim. Sci. 82(E-Suppl. 1):E313-E328.

Druet, T., C. Schrooten, and A. P. W. de Roos. 2010. In silico genotyping of thousands of SNPs in dairy cattle for the EuroGenomics project. Commun. No. 0137 in Proc. 9th World Congr. Genet. Appl. Livest. Prod., Leipzig, Germany. Gesellschaft für Tierzuchtwissenschaften e. V., Gießen, Germany.

Ducrocq, V., S. Fritz, F. Guillaume, and D. Boichard. 2009. French report on the use of genomic evaluation. Interbull Bull. 39:17-21.

EuroGenomics. 2010. Further improvement of genomic evaluation within EuroGenomics. Press release, December 15, 2010. Accessed December 22, 2010. http://www.vikinggenetics.com/dk/news/ Press\%20release\%20Dec\%202010.pdf.

Grisart, B., F. Farnir, L. Karim, N. Cambisano, J.-J. Kim, A. Kvasz, M. Mni, P. Simon, J.-M. Frère, W. Coppieters, and M. Georges. 2004. Genetic and functional confirmation of the causality of the DGAT1 K232A quantitative trait nucleotide in affecting milk yield and composition. Proc. Natl. Acad. Sci. USA 101:2398-2403.

Hayes, B. J., J. Pryce, A. J. Chamberlain, P. J. Bowman, and M. E. Goddard. 2010. Genetic architecture of complex traits and accuracy of genomic prediction: Coat colour, milk-fat percentage, and type in Holstein cattle as contrasting model traits. PLoS Genet. 6:31001139. doi:10.1371/journal.pgen1001139.
Illumina. 2010a. BovineHD Genotyping BeadChip. Accessed December 14, 2010. http://www.illumina.com/Documents/products/ datasheets/datasheet_bovineHD.pdf.

Illumina. 2010b. BovineSNP50 Genotyping BeadChip. Accessed December 14, 2010. http://www.illumina.com/Documents/products/ datasheets/datasheet_bovine_snp5O.pdf.

Illumina. 2010c. GoldenGate Bovine3K Genotyping BeadChip. Accessed December 14, 2010. http://www.illumina.com/Documents/ products/datasheets/datasheet_bovine3K.pdf.

Interbull. 2010. GEBV test-August 2010. Accessed December 21, 2010. http://www.interbull.org/index.php?option=com content\&view $=$ article\&id $=82$ :gebv-test-results-august-2010\&catid $=4$ :organization\&Itemid $=119$.

LIC. 2008. Inside LIC. C. Bayly, ed. Livestock Improvement Corporation, Hamilton, New Zealand.

Loberg, A., and J. W. Dürr. 2009. Interbull survey on the use of genomic information. Interbull Bull. 39:3-13.

Meuwissen, T. 2010. Use of whole genome sequence data for QTL mapping and genomic selection. Commun. No. 0018 in Proc. 9th World Congr. Genet. Appl. Livest. Prod., Leipzig, Germany. Gesellschaft für Tierzuchtwissenschaften e. V., Gießen, Germany.

Meuwissen, T. H., B. J. Hayes, and M. E. Goddard. 2001. Prediction of total genetic value using genome-wide dense marker maps. Genetics 157:1819-1829.

Misztal, I. 2006. Challenges of application of marker assisted selection-A review. Anim. Sci. Pap. Rep. 24:5-10.

Nieuwhof, G. J., K. T. Beard, K. V. Konstantinov, P. J. Bowman, and B. J. Hayes. 2010. Implementation of genomics in Australia. Preliminary proceedings of 2010 Interbull meeting, Riga, Latvia, 5 pages. Accessed December 22, 2010. http://www.interbull.org/ images/stories/Nieuwhof_Implementation_of_genomics_in_ Australia.pdf.

Reinhardt, F., Z. Liu, F. Seefried, and G. Thaller. 2009. Implementation of genomic evaluation in German Holsteins. Interbull Bull. 40:219-226.

Soller, M. 1994. Marker assisted selection-An overview. Anim. Biotechnol. 5:193-207.

Spelman, R. J., J. Arias, M. D. Keehan, V. Obolonkin, A. M. Winkelman, D. L. Johnson, and B. L. Harris. 2010. Application of genomic selection in the New Zealand dairy cattle industry. Commun. No. 0311 in Proc. 9th World Congr. Genet. Appl. Livest. Prod., Leipzig, Germany. Gesellschaft für Tierzuchtwissenschaften e. V., Gießen, Germany.

Stormont, C. 1967. Contribution of blood typing to dairy science progress. J. Dairy Sci. 50:253-260.

Van Doormaal, B. J., G. J. Kistemaker, P. G. Sullivan, M. Sargolzaei, and F. S. Schenkel. 2009. Canadian implementation of genomic evaluations. Interbull Bull. 40:214-218.

Van Tassell, C. P., T. P. L. Smith, L. K. Matukumalli, J. F. Taylor, R. D. Schnabel, C. T. Lawley, C. D. Haudenschild, S. S. Moore, W. C. Warren, and T. S. Sonstegard. 2008. SNP discovery and allele frequency estimation by deep sequencing of reduced representation libraries. Nat. Methods 5:247-252.

VanRaden, P. M. 2008. Efficient methods to compute genomic predictions. J. Dairy Sci. 91:4414-4423.

VanRaden, P. M., and M. E. Tooker. 2010. Gains in reliability from combining subsets of $500,5,000,50,000$ or 500,000 genetic markers. J. Dairy Sci. 93(E-Suppl. 1):534. (Abstr.)

VanRaden, P. M., C. P. Van Tassell, G. R. Wiggans, T. S. Sonstegard, R. D. Schnabel, J. F. Taylor, and F. S. Schenkel. 2009. Invited review: Reliability of genomic predictions for North American Holstein bulls. J. Dairy Sci. 92:16-24.

Vazquez, A. I., G. J. M. Rosa, K. A. Weigel, G. De los Campos, D. Gianola, and D. B. Allison. 2010. Predictive ability of subsets of single nucleotide polymorphisms with and without parent average in US Holsteins. J. Dairy Sci. 93:5942-5949.

Weigel, K. A., G. de los Campos, A. I. Vazquez, G. J. M. Rosa, D. Gianola, and C. P. Van Tassell. 2010. Accuracy of direct genomic values derived from imputed single nucleotide polymorphism genotypes in Jersey cattle. J. Dairy Sci. 93:5423-5435. 
Wiggans, G. R., T. A. Cooper, and P. M. VanRaden. 2010a. Cow adjustments for genomic predictions of Holsteins and Jersey bulls. J. Dairy Sci. 93:533-534. (Abstr.)

Wiggans, G. R., T. S. Sonstegard, P. M. VanRaden, L. K. Matukumalli, R. D. Schnabel, J. F. Taylor, J. P. Chesnais, F. S. Schenkel, and C. P. Van Tassell. 2009a. Genomic evaluations in the United States and Canada: A collaboration. ICAR Tech. Ser. 13:347-353.

Wiggans, G. R., T. S. Sonstegard, P. M. VanRaden, L. K. Matukumalli, R. D. Schnabel, J. F. Taylor, F. S. Schenkel, and C. P. Van Tassell. 2009b. Selection of single-nucleotide polymorphisms and quality of genotypes used in genomic evaluation of dairy cattle in the United States and Canada. J. Dairy Sci. 92:3431-3436.

Wiggans, G. R., and P. M. VanRaden. 2010. Improved reliability approximation for genomic evaluations in the United States. J. Dairy Sci. 93(E-Suppl. 1):533. (Abstr.)

Wiggans, G. R., P. M. VanRaden, L. R. Bacheller, M. E. Tooker, J. L. Hutchison, T. A. Cooper, and T. S. Sonstegard. 2010b. Selection and management of DNA markers for use in genomic evaluation. J. Dairy Sci. 93:2287-2292. 